\title{
Development of a Smart Monitoring and Evaluation Framework for Hybrid Renewable Mini-grids
}

\author{
Babak Ravanbach \\ DLR Institute of Networked Energy \\ Systems \\ Carl-von-Ossietzky-Str. 15, 26129 \\ Oldenburg, Germany \\ Email: Babak.Ravanbach@,dlr.de
}

Karsten von Maydell

DLR Institute of Networked Energy Systems

Carl-von-Ossietzky-Str. 15, 26129

Oldenburg, Germany

Email: Karsten.Maydell@,dlr.de

Golden Makaka

University of Fort Hare

Ring Road, Alice, 5700

South Africa

Email: Gmakaka@ufh.ac.za

Kittessa Roro

Council for Scientific and Industrial Research (CSIR)

PO Box 395, Pretoria, 0001, South Africa

Email: KRoro@csir.co.za

\author{
Meike Kühnel \\ DLR Institute of Networked Energy \\ Systems \\ Carl-von-Ossietzky-Str. 15, 26129 \\ Oldenburg, Germany \\ Email: Peter.Klement@,dlr.de
}

E. Ernest van Dyk

Nelson Mandela University

PO Box 77000, Port Elizabeth, 6031, South Africa

Email: Ernest.vanDyk@mandela.ac.za

\author{
Mahali Elizabeth Lesala \\ University of Fort Hare \\ Ring Road, Alice, 5700 \\ South Africa \\ Email: MLesala@ufh.ac.za
}

\author{
Benedikt Hanke \\ DLR Institute of Networked Energy \\ Systems \\ Carl-von-Ossietzky-Str. 15, 26129 \\ Oldenburg, Germany \\ Email: Benedikt.Hanke@dlr.de \\ Monphias Vumbugwa \\ Nelson Mandela University \\ PO Box 77000, Port Elizabeth, 6031, \\ South Africa \\ Email: $\underline{\text { s218207115@mandela.ac.za }}$
}

\author{
Ngwarai Shambira \\ University of Fort Hare \\ Ring Road, Alice, 5700 \\ South Africa \\ Email: 201927103@ufh.ac.za
}

\begin{abstract}
Hybrid renewable mini-grids have emerged as a viable solution for providing reliable, environmentally friendly electricity to remote communities. An affordable and grid-quality supply of energy can open new possibilities for socioeconomic progress. As part of a joint project between South Africa's Eastern Cape province and Germany's state of Lower Saxony a Photovoltaic (PV) hybrid mini-grid is developed in the municipality of Upper Blinkwater in Eastern Cape for a rural community of 70 households with $\mathbf{9 0 \%}$ living off of social grants and no access to the main national grid. The aim of this work is to develop a smart Monitoring and Evaluation Framework (MEF) for hybrid renewable mini-grids by integrating cutting-edge technologies in a scalable platform of replicable solutions towards connecting the mini-grid with diverse stakeholders with enhanced observability of both generation and consumption profiles. The MEF provides the opportunity to streamline the flow of real-time energy data (generation, consumption, and storage) from the system to generate accurate and high-resolution datadriven load profiles for rural households. Simultaneously, the interrelation between energy access and social development will be studied and analyzed.
\end{abstract}

Keywords- Hybrid Renewable Mini-grids; Monitoring and Evaluation, PV Mini-grids; Energy Access; Smart Minigrids; Rural Household Load Profiles; Social Development

\section{INTRODUCTION}

\section{A. Energy Access}

Goal 7 of Sustainable Development Goals advocates universal access to affordable, reliable, modern energy services. Access to energy is an essential prerequisite to achieving many sustainable development goals that extend far beyond the energy sector, such as eradicating poverty, increasing food production, providing clean water, improving public health, enhancing education, and creating economic opportunity [1].

According to the World Bank's report [2], from 1997 to 2017 , the proportion of the global population with access to electricity increased from $78 \%$ to $89 \%$ (table 1 ), with the number of people living without electricity dropping to just below 1 billion [1]. 
TABLE 1: WORLDWIDE ACCESS TO ELECTRICITY (2017)

\begin{tabular}{|l|c|}
\hline Access to electricity & Population \% \\
\hline Worldwide & 88.9 \\
\hline Urban & 97.4 \\
\hline Rural & 78.7 \\
\hline
\end{tabular}

More than half of this population lives in SubSaharan Africa, and rapid population growth is projected to outpace grid expansion.

The electrification rate in Sub-Saharan Africa is 67\%, and it drops as low as $28 \%$ in rural areas [3]. In many countries national utilities lack the resources to finance grid extensions to remote rural areas, where low levels of electricity consumption and limited ability to pay often make these extensions uneconomic. Average cost of extending the grid to rural consumers in Africa is estimated at $\$ 2,000 /$ connection [4], while the average cost of $11 \mathrm{kV}$ power line is around $\$ 20,000 / \mathrm{km}[5]$.

Renewable energy hybrid mini-grids are a suitable alternative for providing reliable, environmentally friendly supply to remote communities. A consistent and affordable supply of energy can open new possibilities for socioeconomic progress. The International Energy Agency projects that mini-grids and stand-alone off-grid systems will play key roles in extending electricity to many rural areas in Africa that do not have access to national grids [6].

Africa has emerged as a dynamic, fast-advancing center for renewable mini-grids. The deployment of PV technologies has been a key driver of growth in minigrid capacity. The abundance of the resource, the distributed nature of technology and decreasing costs are leading solar PV to become a viable alternative for meeting a wide range of electricity services in areas largely underserved by the national grid. The cumulative capacity has increased from $231 \mathrm{MW}$ in 2008 to nearly $1.2 \mathrm{GW}$ in 2017 [6]. The World Bank estimates that 140 million rural Africans will gain access to electricity served by mini-grids by 2040 [7].

\section{B. South Africa Electrification}

For South Africa, the electrification is an important national target, as around $15 \%$ of all households are still not electrified. According to the Integrated Resource Plan 2019 (IRP2019), South Africa's electricity infrastructure development plan from the Department of Energy, South Africa still has 3-million households without access to grid-based electricity in 2019 [8]. The Eastern Cape has the lowest grid connection in South Africa with the rate of $64.5 \%$ [9].

According to the Eskom [10], South African electricity public utility, the nearest proposed substation to the community of Upper Blinkwater (UB) will be developed in Phase 4 of the grid extension plan with an estimated time period of 6 to 8 years (figure 1). Based on estimates from the local sources $25 \%$ of all communities in the Eastern Cape will be connected to the grid in 8 to 15 years at the earliest. As a result, the inhabitants of these villages economically and socially lag behind and migrate to other areas.

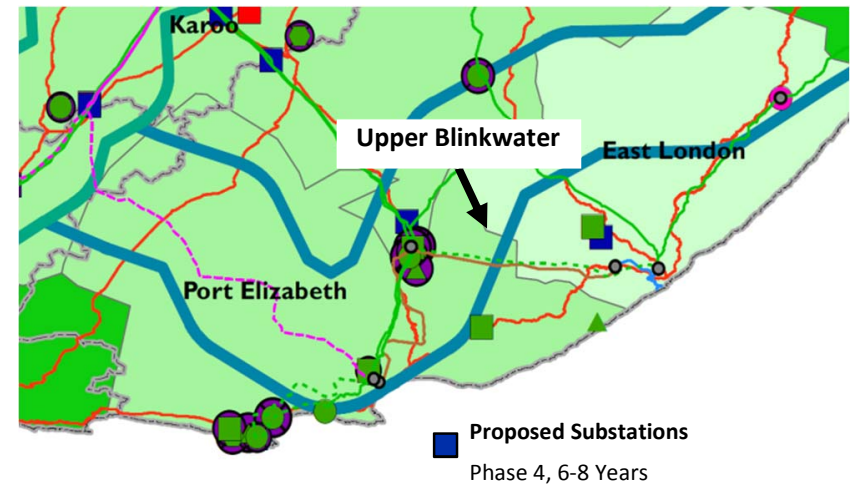

Fig. 1: Layout of the Eskom grid plan near the community

South Africa has approximately $45 \mathrm{GW}$ of generating capacity, of which about $9 \%$ is currently renewable energy and $86 \%$ is coal. The Department of Energy has committed South Africa to increasing renewable energy generation from around $4 \mathrm{GW}$ to $13.225 \mathrm{GW}$ by 2025 , through its Integrated Resource Plan. The potential for the use of solar energy is extremely favorable, with direct normal irradiance averaging over $7.0 \mathrm{kWh} / \mathrm{m}^{2} /$ day [9] and the sunshine duration of up to 2,500 hours/year [11]. Solar irradiance is also relatively uniform across the country, and forms the best renewable resource available for mini-grids. Figure 2 shows the solar irradiation $\left(\mathrm{kWh} / \mathrm{m}^{2}\right)$ for South Africa [12].

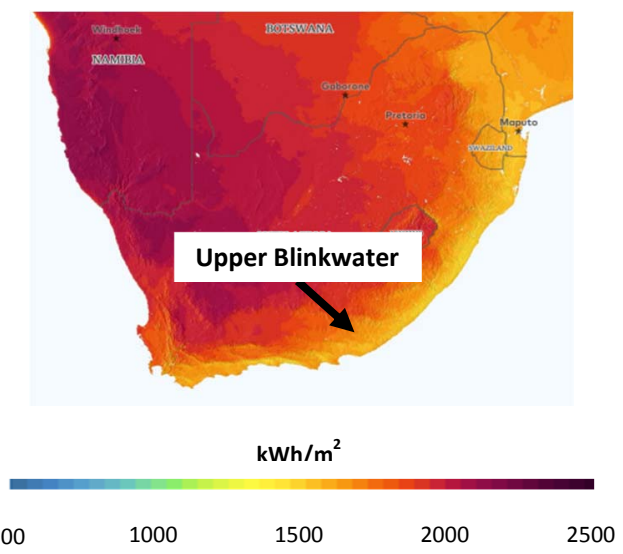

Fig. 2: Solar energy resources (solar irradiation $\mathrm{kWh} / \mathrm{m} 2$ ) 


\section{HYBRID RENEWABLE MINI-GRID PROJECT}

As part of a joint project between South Africa's Eastern Cape province and Germany's state of Lower Saxony, with funding from BMZ (Federal Ministry for Economic Cooperation and Development) through GIZ (Deutsche Gesellschaft für Internationale Zusammenarbeit: German Corporation for International Cooperation), a PV hybrid mini-grid was designed and developed in the municipality of UB in Eastern Cape, South Africa for a rural community of 70 households with $90 \%$ living off of social grants and no access to the main national grid [11].

The aim of the project is to demonstrate a solution for an economically and ecologically sustainable energy supply to non-electrified rural communities.

The hybrid mini-grid schematic and components are shown in the following figure 3 and table 2 respectively. Figure 4 illustrates the single-diagram of the system with AC-coupled components. The 3 phase AC-coupled system will feed individual houses with three arrays of single-phase connections.

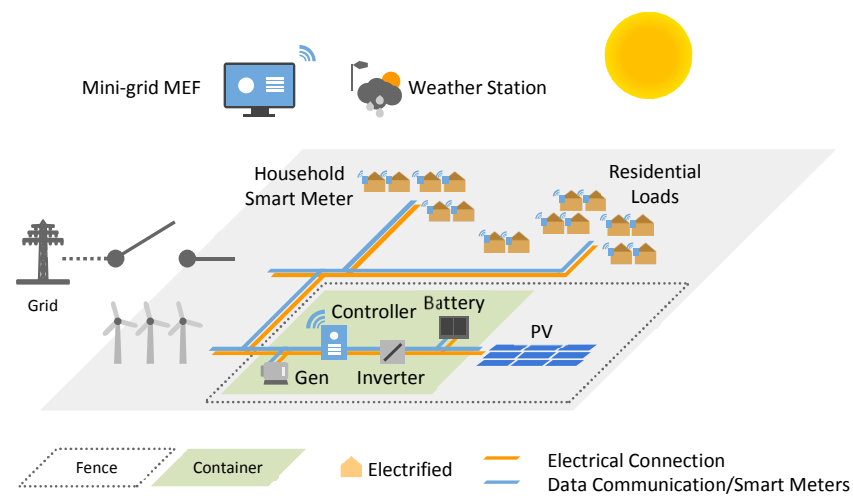

Fig. 3: Project schematic, components and connection

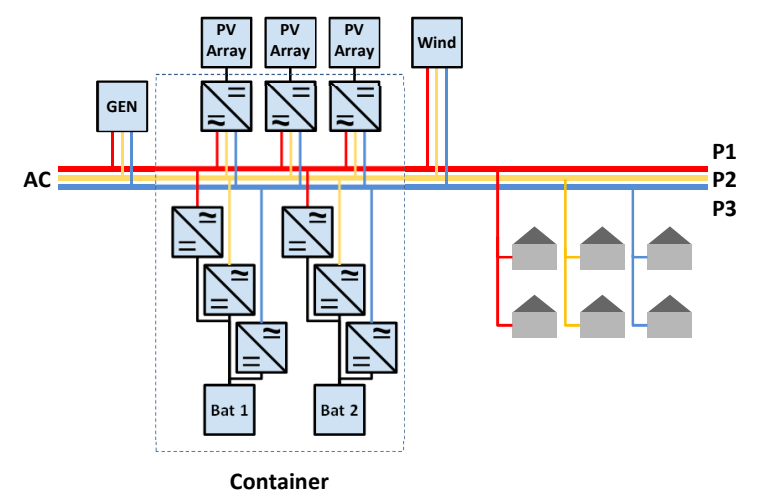

Fig. 4: Mini-grid single-line diagram (3 phases are colored as red, yellow, blue)

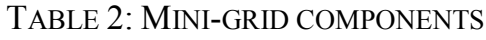

\begin{tabular}{|l|l|}
\hline Component & Capacity \\
\hline PV & $75 \mathrm{~kW}_{\text {peak }}$ \\
\hline Diesel generator & $44 \mathrm{~kW}$ \\
\hline PV Inverter & $60 \mathrm{~kW}\left(3^{*} 20 \mathrm{~kW}\right)$ \\
\hline Battery Inverter & $6-9 \mathrm{~kW}$ \\
\hline Storage (Li-Ion Battery) & $130 \mathrm{kWh}(2 * 65 \mathrm{kWh})$ \\
\hline
\end{tabular}

In the first part of the project the generation is provided only from a PV system. In the second part of the project the possibilities of integrating a wind generation system is studied and analyzed.

The scope of this paper does not include the wind integration phase. In summary the overall objective of this phase involves the local-to-local knowledge transfer and the provision of technical support in the analysis and sizing of the local wind energy resources, followed by the sourcing and installation of small wind turbines.

The Eastern Cape Government, through the Department of Economic Development, Environmental Affairs and Tourism (DEDEAT) is collaborating with South Africa Wind Energy Project (SAWEP) to add the wind component into the UB mini-grid project. SAWEP is supported by the United Nations Development Programme (UNDP) with resources from the Global Environment Facility (GEF), and implemented by the South African National Energy Development Institute (SANEDI) on behalf of the Department of Minerals Resources and Energy (DMRE), will fund the integration of small scale wind turbines, between 21 to $24 \mathrm{~kW}$ capacity for Phase 2 of the project.

The CSIR Energy Centre is leading the wind integration phase of the project and is responsible for the resource assessment, energy and power system modeling and knowledge transfer to the community.

The high-level resource assessment consisted of an on-site wind resource measurement campaign, and the modeling of the wind climate and the proposed wind farm for the site. Wind resource measurement was conducted through the siting of a Lidar and a wind mast at two separate locations, and lasted for 6 months due to time constraints. As a result, the wind climate, Figure 5, and subsequent wind farm development model were created using a mesoscale ${ }^{1}$ modeled dataset (SWAP dataset) which was then validated against the afore mentioned measured dataset. The wind climate was evaluated using $\mathrm{WAsP}^{\overparen{ } 2}$ and the expected energy

\footnotetext{
${ }^{1}$ Mesoscale meteorology is the study of atmospheric phenomena with typical spatial scales between 10 and $1000 \mathrm{~km}$ (https://atmos.washington.edu/academic/mesoscale.html) ${ }^{2}$ The WAsP software suite is the industry-standard for wind resource assessment, siting and energy yield calculation for wind turbines and wind farms. (https://www.wasp.dk)
} 
production was calculated for the wind farm development model.

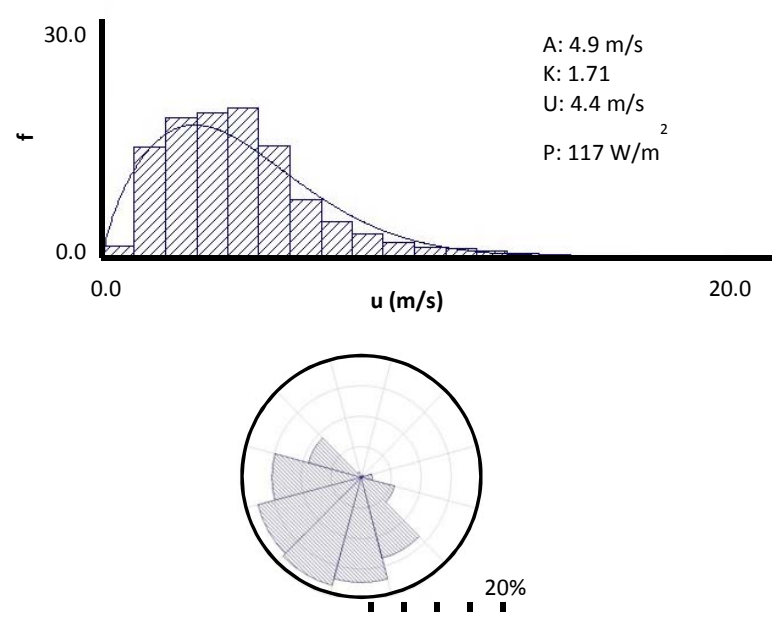

Fig. 5: Generalized wind climate for proposed wind turbine location

A two to six-turbine system was chosen to accommodate future increases in household demand, productive energy use or additional household connections. The expected energy generation for 6 local available WTG's (3.5 kW/WTG) is shown in figure 6 .

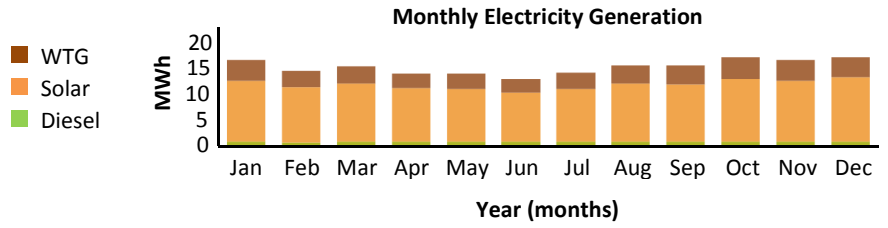

Fig. 6: Monthly Electricity Generation for generic six-turbine system included in the mini-grid

The need for such a project stems from: 1) lack of public knowledge on hybrid small-scale rural and standalone renewable energy system planning, costing, and operation, and 2) remaining national challenge of shortages in technical skills development. The project design and implementation must be done in collaboration with the local community. Herein, the term "community" includes all involved e.g. the villagers, the municipality, the project managers, the owner engineers, etc.

This paper aims at developing a framework to continuously and sustainably collect data from the minigrid and the community to accomplish the following objectives:

1. Monitor the electricity generation and track the evolution of household consumption from having no access to energy to a reliable grid-quality electricity service
2. Study and analyze the socio-economic impact on the community as a whole after gaining electricity access

\section{SMART MONITORING AND EVALUATION FRAMEWORK}

With little experience in developing and operating mini-grids, there is little practical data available to scaleup or transfer the technology to other regions. A number of challenges have been experienced in the course of implementing mini-grids, including:

- Operational challenges due to remoteness and complexity of these systems

- Ensuring that the system is functioning according to the initial design specifications

- Integration of smart technologies to support and maintain sustainable data flow including transfer and storage

- Data interface and reporting to various stakeholders

The IRP2019 indicates that the cost of providing grid connections has increased as the served communities become more remote. There is therefore a need to quantify the off-grid and mini-grid opportunity and put in place the necessary frameworks for accelerated development [8].

Successful implementation of mini-grids requires the right set of technologies, access to financing, consumerfriendly payment system, an appropriate regulatory environment, social facilitation, institutional implementation, environmental impact evaluation, human capitalization and training, and implementing a robust, reliable, and sustainable Monitoring and Evaluation Framework (MEF).

As a first of its kind service delivery approach in the South African context it is important to evaluate not only the technical success, but also the social, economic and institutional impacts of the technological implementation. A sustainable MEF can bridge the gap between the design and operation in the long run. It can eventually guarantee the flow of essential data to various stakeholders, including governmental organizations, utility operators, consumers, research institutes, investors, universities, and local authorities to manage, evaluate and optimize the system.

\section{A. Key Performance Indicators}

In order to monitor, evaluate and optimize the minigrid, a set of Key Performance Indicators (KPIs) is developed through a technical workshop with all the 
stakeholders, including local universities, the municipality of UB and other strategic and executive partners mentioned in the Acknowledgement section.

In the first step, the main features of MEF and the integrated components are specified. Two types of data sources, energy (i.e. generation, consumption, storage, power quality, etc.) and non-energy (i.e. revenues from prepaid electricity meters) are defined as the base to parameterize the mini-grid system.

In the next phase KPIs are categorized into five domains including: technical, operational, financial, social, and environmental according to the specific needs of each stakeholder (figure 7).

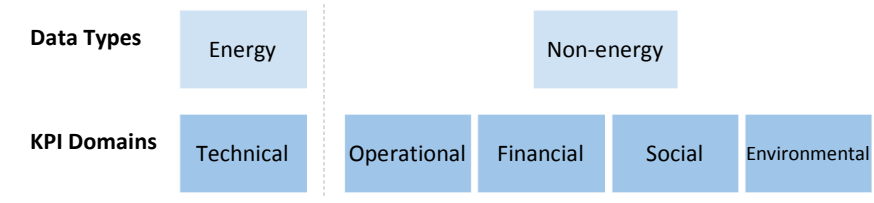

Fig. 7: KPI data types and domains

Sustainable flow of data measured and collected from the mini-grid not only can support the decision makers and operators to monitor and evaluate the system, the KPIs will be further used as a basis to generate a comprehensive report for each stakeholder based on their specific demand and requirement (figure 8).

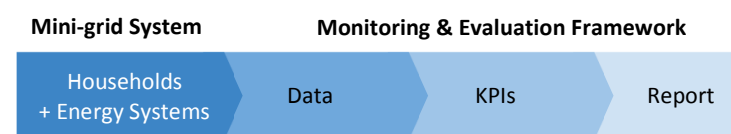

Fig. 8: Flow of data from the mini-grid to the comprehensive report

\section{B. Data Acquisition and Management}

With the advancement of smart grid technologies, it is becoming easier to monitor and track the production of each component of hybrid systems. Beyond generation technologies, innovations in enabling components, including smart control systems that take advantage of the internet of things, have created opportunities to better integrate large shares of solar and wind in isolated power systems. Cloud-based monitoring solutions for mini-grids integrate the communications hardware in meters and transmit consumption data to a central gateway. These applications reduce electricity cost and increase the reliability of electricity supply by optimizing consumption, thus reducing generation and storage (e.g. battery size) costs [13]. Integrating a smart energy management is also critical to ensuring stability and quality of supply. Smart energy management enables real-time and cost-effective monitoring and management of all the assets on a mini-grid thus improving resource efficiency.
The following features have been considered as the base requirements for the MEF system:

- Data collection (economic, automatic, accuracy, resolution, compatibility)

- Data transfer and storage (economic, reliable, automatic, wireless)

- Ease of access to data (internet-based)

- Security of data (secure servers, authenticated)

- Scalability (envisioning the growing demand and community size)

In addition to data acquisition for monitoring, the system is integrated with control and diagnostic features. The mini-grid controller unit is programmed to control the load flow and trigger load shedding according to a set of pre-defined and adjustable load level scenarios. The mini-grid controller communicates with the inverters, battery and the generator to adjust the feed-in from the renewable generation to the demand. The minigrid MEF also provides critical and timely data to the operator for diagnostic and operational purposes.

With respect to monitoring and analyzing household consumption the MEF is aimed at providing the following advantages: real-time consumption monitoring, analysis of the demand evolution, and seamless data access to all stakeholders.

Based on the selected KPIs and the overall project requirements a data flow scheme is designed and the appropriate metering and telecommunication technologies, software modules, and data interfaces are integrated as shown in figure 9.

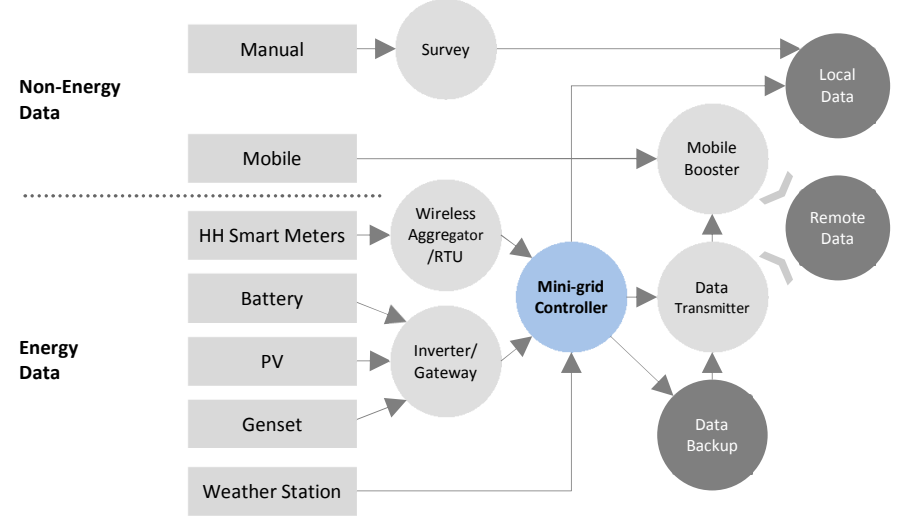

Fig. 9: Mini-grid Monitoring \& Evaluation Frame work (data acquisition components)

The system consists of smart metering devices measuring real-time data from every component in the system including: household smart meters, generation and storage meters, and a state-of-the-art weather station. 
The measured data is collected and fed to the mini-grid controller. The mini-grid controller is set up to automatically push the data to a cloud-based portal.

\section{DATA-DRIVEN HouseHOLD LOAD PROFILES}

Standard urban household load profiles are useful and essential in the field of energy research, and there has already been significant scientific contribution to this subject. In contrast, there have been relatively less efforts to address rural load profiles connected to renewable hybrid mini-grids, especially for rural communities with no access to electricity after gaining a reliable grid-quality service, as the load profiles would evolve over time.

For example in [14] the authors develop a method to synthetically generate representative profiles for two seasons (summer and winter) and for two income levels from historical data and relating the hourly customer load profiles to household income in South African context. In this particular case and similar studies the profiles are constructed based on historical data from averaged urban grid-connected households with the assumption that rural main-gird consumers will follow similar consumption patterns.

The limiting technical challenge for mini-grids in general is on handling fluctuating generation and times of peak demand, rather than average consumption [9]. Electrifying a rural community with a renewable energy based mini-grid poses even more unique challenges. For example, the limitation of mini-grid energy supply due to the fluctuating nature of renewable resources, and the evolution of unknown consumer behavior and community growth after gaining access to electric for the first time should be taken into account when developing such load profiles.

In the past, many approaches have been developed to estimate the load profile. The following paragraphs point out the evolution of load profile estimation from a binary approach to a high-resolution real-time data acquisition and load profile generation.

\section{A. Past: Binary Approach to Electricity Access}

In the past, electricity access was measured in a binary way. This typically meant "having or not having an electricity connection". Its focus on only one attribute, access to grid, provides a simplistic and often distorted image because it fails to determine how this access translates into reliable, affordable and modern service. In addition, the traditional counting method is static and fails to account for evolving technology solutions.

\section{B. Present: SE4ALL Multi-tier Framework}

Binary metrics such as whether a household has an electricity connection and whether a household cooks with non-solid fuels are not helpful in understanding the phenomenon of expanding energy access and how it impacts socio-economic development.

The SE4ALL Multi-tier Framework (MTF) [15] redefines energy access to redefines energy access to fill the gaps in the binary access measurement (figure 10).

\begin{tabular}{|ccc|}
\hline Past & Present & Future \\
\hline $\begin{array}{c}\text { Binary Approach to } \\
\text { Electricity Access }\end{array}$ & SE4ALL & Data-driven \\
Multi-tier Framework & Load Profiles
\end{tabular}

Fig. 10: Evolution of approaches to energy access determination and load profile, past, present and future

As illustrated in table 3 MTF acknowledges that energy access is a spectrum of service levels (or tiers) consumed by households, productive engagements and community facilities. It also focuses on the quality of energy service.

TABLE 3: SE4ALL MULTI-TIER FRAMEWORK

\begin{tabular}{|c|l|c|l|}
\hline Tier & Power & Hour/Day & Application \\
\hline 0 & No Electricity & & No application \\
\hline 1 & $\begin{array}{l}\text { Very Low, Min } \\
3 \mathrm{~W}\end{array}$ & 4 & Lighting, Phone Charger, Radio \\
\hline 2 & Low, Min 50W & 4 & + Television, Fan \\
\hline 3 & $\begin{array}{l}\text { Medium, Min } \\
200 \mathrm{~W}\end{array}$ & 8 & + Pumps, Refrigeration, Rice Cooker \\
\hline 4 & High, Min 800W & 16 & + Washing Machine, Iron, Toaster, Microwave \\
\hline 5 & $\begin{array}{l}\text { Very High, Min } \\
2000 \mathrm{~W}\end{array}$ & 23 & + AC, Vacuum Cleaner \\
\hline
\end{tabular}

With all its advantages the MTF may fall short in handling the following scenarios:

- Real-time consumption/generation data

- Integration of hybrid renewable energy systems

- Growing demand and evolving consumer behavior

- Ever-improving appliances and introduction of new products

- Accuracy and resolution of data

\section{Future: Data-driven Load Profiles}

Mini-grids provide energy services tailored and optimized for an estimated consumer load profile. For renewable hybrid mini-grids, the fluctuating nature of resources adds more complexity to the challenge of maintaining the energy balance. Therefore, having access to accurate load profiles is indispensable for the initial design and optimization during the operation.

In the preliminary design phase of the project the individual household demand is characterized and 
estimated according to the standard pre-defined set of load profiles obtained from MTF, and consequently the mini-grid generation and storage capacity is modeled and calculated based on these standard estimated set of load profiles.

The aim of the project is to design and develop a sustainable data acquisition framework, so when the mini-grid system starts its operation in the future, the system would enable access to individual household consumption data to generate high resolution (up to 1 minute) load profiles to fill the gap between the standard pre-defined and the real demand values.

Due to delays in the project implementation the data is not yet accessible; however, the plan is to collect data for duration of 6 months after the start of operation and publish the results in the following publication.

\section{GENERATTION OF AN AVERAGE RURAL HOUSEHOLD LOAD PROFILE FOR SOUTH AFRICA}

In this section a method for estimation of an average rural South African household load profile is presented. The generated load profiles will be used as the baseline to compare and analyze the evolution of demand over time when the MEF goes online.

In the work of [14], a load profile prediction model for residential consumers in South Africa is presented. The work estimates the average rural household load profile for two income levels $(1,000$ and 10,000 Rand/month) and for two different seasons (summer and winter). Load readings are collected for 10 years (1994 2004), excluding public holidays.

The generalized South African rural household load profiles from the work of [14] are taken as the reference and further manipulated and interpolated based on three correlating parameters, income, annual electricity consumption, and weather conditions, and then adjusted through the following steps to regenerate a baseline load profile for the community of UB:

1. Extracting the Summer and Winter load profiles for households earning R 1,000 and R 1,0000

2. Adjusting the data to correspond to the summer and winter season of the community of UB.

3. Scaling each profile to the average household income level of the community of UB

4. Scaling the load profile to the energy consumption of an average rural South African household
5. Scaling the load profiles based on the ratio of number of residents in UB compared to the national average

The results for the baseline load profiles are shown in the result section.

\section{SOCIAL DEVELOPMENT}

The aim of the study is to evaluate the social and economic impacts of the hybrid mini-grid system in the UB project. To achieve this, the baseline information was established. This is the survey documenting the current and existing state of the community to provide a picture of the status quo, from which changes in the livelihood and wellbeing of the community/households recipients resulting from the implementation of the minigrid can be measured. Likewise, the question of how much energy is required and whom the end-user of the energy generated is central to "load profiling and determination of energy usage patterns". Therefore, thorough information on the probable number of households connecting to the mini-grid is essential. The results would be used to indicate if the project affected the desired effects on the community and most specifically, will clarify how and to what extent access to electricity and such infrastructure contribute to economic and social development.

\section{A. Social Development by Definition}

To alleviate poverty, any development intervention must aim at improving the status quo and overall living conditions of rural populations. By definition, social development is about improving the economic status and wellbeing of especially the socially or economically disadvantaged [16]. It encompasses a variety of social aspect including population, gender aspects, education, employment, income, housing and access to basic services such as, health facilities and access to energy [17]. For the purpose of this study, these basic indicators provide a yardstick for assessing the impact of the minigrid energy with regard to socio-economic aspects and development. This is particularly important for South Africa to correct the imbalances in access to such important basic services and electrify the homes of the many that were previously denied access because of the racially based structure of the electricity supply industry [18].

\section{B. Rural Electrification and Social Development}

Energy regardless of its source is the driving force for development. Energy facilitates all facets of social and economic activities. It is therefore, deemed critical for improving quality of life and eradicating poverty. Without affordable and reliable energy as explicitly set 
out in the United Nations' Sustainable Development Goals, energy poor households are subject to an outright denial of modern services. Consequently, their livelihoods are critically hampered and they remain trapped in the vicious cycle of poverty.

Many low-income and rural households make use of 'traditional' forms of energy such as dung, paraffin, wood and coal [19]. The gathering of the fuel-wood and dung to meet the basic energy needs has been the responsibility that bears much of the adverse effects on women and their children [20]. Women spend hours collecting wood and preparing meals on highly inefficient and unhealthy means of cooking. The time they could have spent on productive activities with greater returns. Hence, their disproportionate lack of access to education and income, and vulnerability to poverty [21]. Likewise, as people grow older, they no longer have the physical strength to collect and gather the wood.

Although the rural areas of South Africa had experienced the largest improvement in access to electricity since the democratic rule, access for the rural population continues to lag behind overall access, by almost 15 percentage points in South Africa [22]. The consistent supply of electricity is needed to facilitate the daily basic lifestyle such as pumping water for drinking and cooking, agricultural uses, lighting and mobile Phone Charging [23].

Modernization and quality of life requires an adequate supply of energy. The off-grid electrification is an effective instrument critical for South Africa in redressing the existing energy poverty gap while equally bringing an inclusive participation of the previously disadvantage in the mainstream economy [24]. Moreover, the main grid energy supply is not sufficient to meet the growing local demand for energy [25] and the concern is on how to meet the future energy demand in order to comply with the SDGs and ensuring the universal access of energy \& electricity for all while maintaining social cohesion [26].

Once a community has access to electricity, it can also have access to safe potable water, better health conditions, food security, as well as lighting and information. Women are the key beneficiaries of the availability and access to energy [27]. Having access to electricity does not only enable them to use appliances for cooking, lighting etc. but emancipate and empower them, as it will release them from the long hours of household work engage in income generating activities within the home and community [21].

\section{Data Collection and Methods of analysis}

UB is a small community located in the outskirts of the urbanized small town, Fort Beaufort. This community has little or no literature to draw inference from; therefore, a baseline survey was conducted to establish the necessary data. A questionnaire was designed and data was collected through face-to-face interviews. The community has 70 households in total but because people migrate only 57 households were interviewed. The statistical data analysis will be used to present the current socio-economic status of the community. In a later stage, the econometric models will be developed for the evaluation of the impacts including the determination of the acceptance of the renewable energy technologies among the individual households.

\section{Areas of Focus for Impact Assessment}

As enclosed in the Reconstruction Development Programme (RDP), meeting the people's most immediate needs such as jobs, land, housing, water, electricity, telecommunications, transport, a clean and healthy environment, health care and social welfare, and shaping the future of the previously excluded communities [28] is a priority for South Africa. The scope of the community profiling was therefore designed according those socio-economic indices and aspects most likely to be affected by the mini-grid. The focus is on general household/community conditions associated to the socio-economic development. Key parameters are as presented in table 4 .

TABLE 4: SOCIAL SURVEY FocUs AREAS

\begin{tabular}{|c|c|}
\hline ID & Social Survey Focus Areas \\
\hline 1 & Household roster and personal characteristics \\
\hline 2 & Education \\
\hline 3 & Employment status \\
\hline 4 & Social security \\
\hline 5 & \begin{tabular}{ll}
\multicolumn{2}{l}{ General household information and service delivery } \\
- & Housing \\
- & Water \\
- & Sanitation and hygiene \\
- & Energy \\
\end{tabular} \\
\hline 6 & Communication and transport \\
\hline 7 & Health, welfare and food security \\
\hline 8 & \begin{tabular}{ll}
\multicolumn{2}{l}{ Household livelihoods } \\
- & Agricultural activities \\
- & Household income sources and expenditures \\
- & Leisure
\end{tabular} \\
\hline 9 & Social cohesion \\
\hline
\end{tabular}

The relationship between social development and these social indicators is crucial, for example, changes in population demographics such as age distribution, household size and migration can change the structure and composition of population which also have effects on the provision and uses of basic services such as energy use, land use and transportation needs. That is, population grows when births increase and decreases 
when people die or migrate [29]. For a sustainable quality of life, it is important to identify population trends and make the necessary projections. This can also be relevant in South Africa where millions of people receive support from government in the form of government subsidy housing (commonly known as RDP houses) and social grants. Social grants are provided to help improve standards of living of the people who are vulnerable to poverty and in need of state support. These generally include older people, people with disabilities, and people with young children [30].

Education on the other hand is in every sense fundamental factors that not only create employment opportunities and raise income levels but it improves the individual mental health capacity, thereby improving their decision-making capabilities and reasoning skills. When educated people have to make choices, they are able to consider consequences associated with such choices. This helps them to have more options and to make better decisions about their lives [31]. Education also influence how people feel about themselves, it enhances their social status and respect from the community and peers, especially in the rural areas where majority of the people are less educated. Likewise, employment provides individuals a sense of worth and is critical for meeting basic human needs [32].

Social development implies progress towards an inclusive society. In any social setting, people are organized into different social groups and they relate with each other in different ways. Social analysis examines the groups' characteristics such as their ethnicity, gender or status in the community and analyses the behavior in relation to their public and private institutions. Closely related to social inclusion is accessibility of basic services. Basic services such as adequate supplies of safe water and adequate sanitation, housing, health care centers, transport and energy are necessary for life, and the failure of municipalities to deliver services can have a severe social impacts such as the unrelenting protests we see in South Africa today [33]. This helps us to comprehend the socio-cultural context in which the project is being implemented so as to nature an environment where they freely express themselves so that they do not feel lack of control over important decisions as well as feelings of alienation and inferiority [34]. If social inclusion is enhanced through participation, the project will be successfully implemented, as they will embrace it.

Poor health, poverty and underdevelopment are coexistent. Poverty increases the chances of poor health because poor people often lack access to public services like safe drinking water, adequate diet and primary health care services. Inadequate access to such services for examples as healthcare and appropriate sanitation leads to the prevalence of death by preventable diseases. This limited access to healthcare for women restricts their access to birth control or education about family planning. This is why fertility rates are generally higher in developing countries [35].

Even if the question of access can be resolved, affordability of basic needs among the poor is a more formidable issue. Education and employment are critical to increasing both the living standards, the purchasing power and affordability of basic needs. Educated people have better employment opportunities and greater stability on the labor market and have better chances to earn more incomes [36]. Similarly, participation in the labor market, especially of women, would reduce time spend on home production, including fertility. A decline in fertility implies the reduced size of the household, reduced decency ratio, and an increase in real household income that would also lead to improved household wellbeing. Thus, these demographic changes will contribute to the achievement of the SDGs [37].

\section{E. Impact Assessment Plan}

Prior to the implementation of the project, community profiling was made and the scope included the factors most likely to be affected by project as indicated in the Table. At this point in time, we only understand based on literature that rural electrification has a number of benefits to offer to this rural community, but what exactly those changes and the direction of the change would be as well as the success of the project is unknown. Following the analysis of the baseline information, a continuous assessment of the key indicators would be done at least every 6 months after the implementation of the mini-grid in three years and every one year thereafter.

The intent of this electrification project is not only to provide access to electricity, but also to also improve the impoverished lives in this community and empower women. Undoubtedly, electricity alone may not be enough to create all the conditions for socio economic conditions. There is a need to empower the community to raise their standard of living. The following are the short and long-term aspirations of the community:

- The pressing for the community of UB is connection to piped water

- Establishment of community based projects and encourages community groups 
- Encourage and promote home vegetable gardens and communal agricultural projects

- Establishment of small home/community based enterprises

As per the policy framework, the Reconstruction and Development program, the community of UB suffers the "second round of exclusion". The community lacks;

- Better housing: mud houses are in a very bad condition with poor sheet roofing

- Access to clean water: water is from the streams, tank and spring by the mountain

- Healthcare center: no clinic at all, the nearest clinic is in Fort Beaufort, about $13.3 \mathrm{~km}$ form the village

- Road infrastructure; the road is poor and slippery in rainy seasons

- Schools; the school is not operational

Generally, the goal for rural electrification is sustainable development. This can only be achieved if energy strategies address the social issues and equally pay much attention to different energy needs of women and men. Such strategies must focus on rectifying and improvements the position of women in the home and the society.

\section{RESULTS}

\section{A. Load Profile Estimation}

The extracted reference load profiles from [14] are shown in figure 11 for both summer and winter and for households earning $\mathrm{R} 1,000$ and $\mathrm{R} 10,000$. Table 5 shows the total household consumption for both Summer and Winter.
Reference Household Load Profile

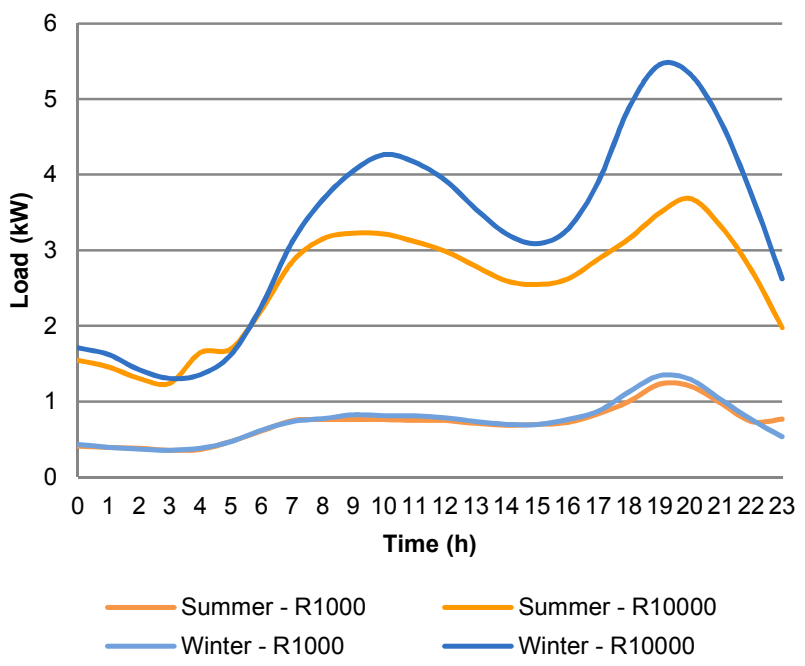

Fig. 11: Reference rural household load profile for summer and winter (for two income levels R1,000 and R10,000)

TABLE 5: REFERENCE PROFILE ANNUAL CONSUMPTION FOR SUMMMER AND WINTER

\begin{tabular}{|l|l|}
\hline Season & Consumption \\
\hline Summer & $9,249 \mathrm{kWh} /$ year \\
\hline Winter & $10,557 \mathrm{kWh} /$ year \\
\hline Average & $9,903 \mathrm{kWh} /$ year \\
\hline
\end{tabular}

According to socio-economic statistics from the report of Raymond Mhlaba Local Municipality [38] the average household income of the UB is determined to be R2,683 (table 6).

TABLE 6: HOUSEHOLD INCOME IN RAYMOND MHLABA LOCAL MUNICIPALITY (UB)

\begin{tabular}{|l|l|}
\hline Annual household income & R 32,200 \\
\hline Monthly household income & R 2,683 \\
\hline
\end{tabular}

According to [39] the average household consumption is $3,584.31 \mathrm{kWh}$.

Using the 2016 data from [40] the average number of household residents in South Africa is determined to be 3.48 , and based on the conducted survey the average number of household residents in the community of UB is determined to be 3.33 (table 7).

TABLE 7: NuMBER OF HOUSEHOLD RESIDENTS

\begin{tabular}{|l|l|}
\hline South Africa (SA) population & $56,522,000$ \\
\hline Number of households in SA & $16,199,000$ \\
\hline Calculated \# of residents/household in SA & 3,48 \\
\hline Estimated \# of residents/household in UB & 3.33 \\
\hline
\end{tabular}

Data corresponding to R2,683 (average household income) was determined by interpolation method from load profiles of R1,000 and R10,000 household earners 
and shown below for summer and winter seasons (figures 12 and 13 respectively).

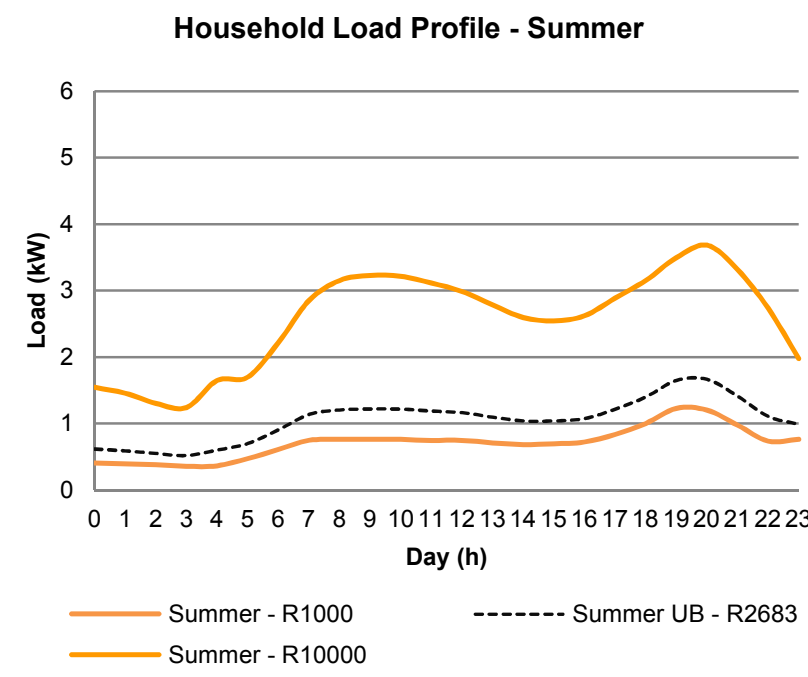

Fig. 12: Household load profile for summer (three income levels)

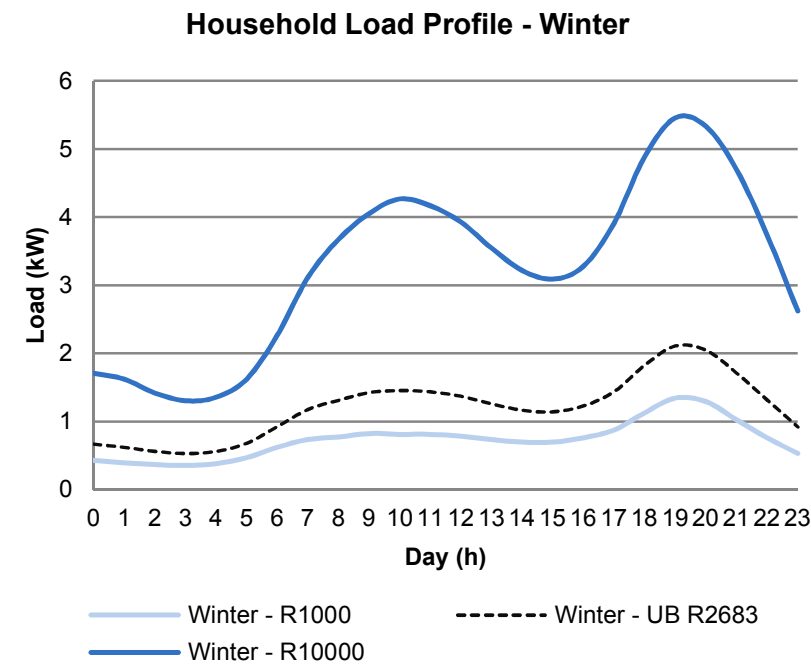

Fig. 13: Household load profile for winter (three income levels)

The scaling factor for the income level R2,683 compared to R1,000 and R10,000 was determined. Household consumption for the load profile of R2,683 was adjusted to match the annual household consumption of $3,940 \mathrm{kWh}$, and the resulting profile is shown in the following figure 14.

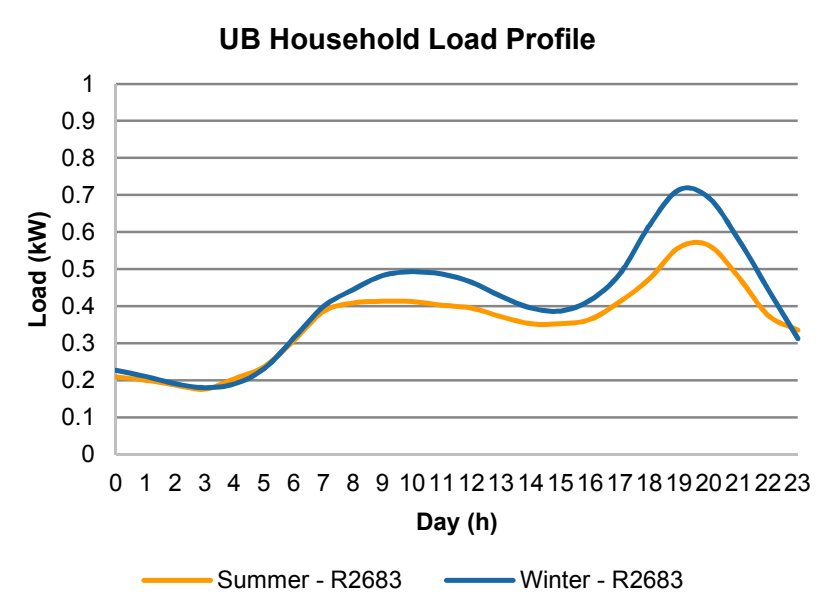

Fig. 14: Household load profile for summer and winter (community average income level)

\section{B. Social Development Indicators}

In this study from the total number of 57 from the total of 70 household were surveyed. In the calculation only 52 household data is used. Others 5 households have been discarded due to incompleteness.

In the following figures the preliminary baseline community information reflecting the social development indicators are graphed. Including;

- Population by Gender (figure 15)

- Household Residents by Gender (figure 16)

- $\quad$ Age (figure 17)

- Family Size (figure 18)

- Household Income (figure 19)

- $\quad$ Education (figure 20)

\section{Community Population By Gender} (Total 173)

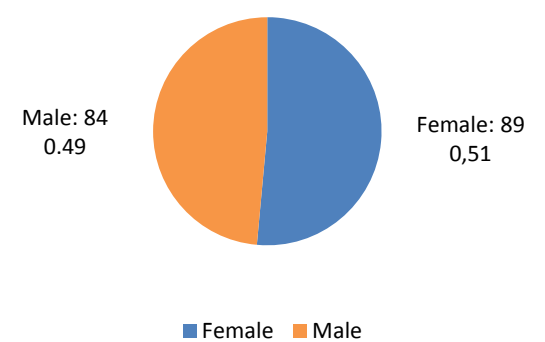

Fig. 15: Community population by gender 
Household Residents by Gender

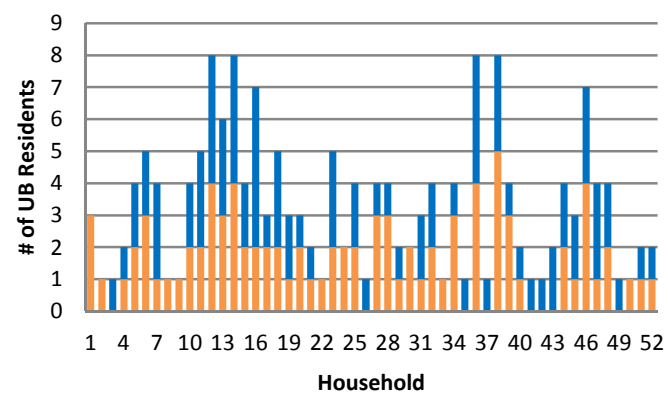

Fig. 16: Number of household residents by gender

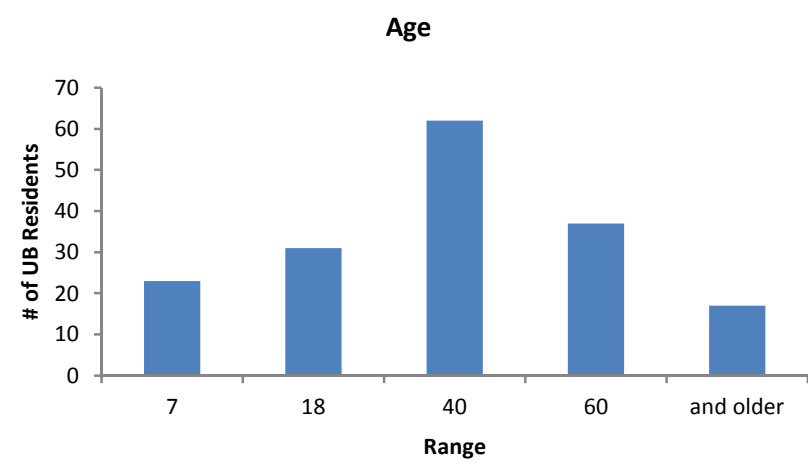

Fig. 17: Age histogram

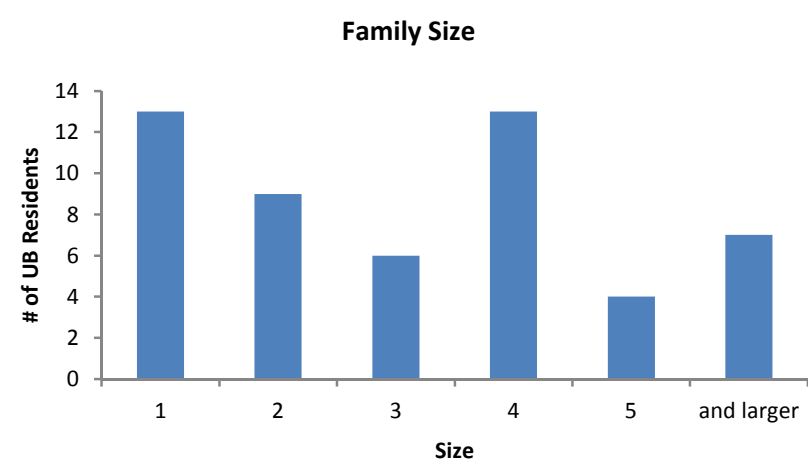

Fig. 18: Family size histogram

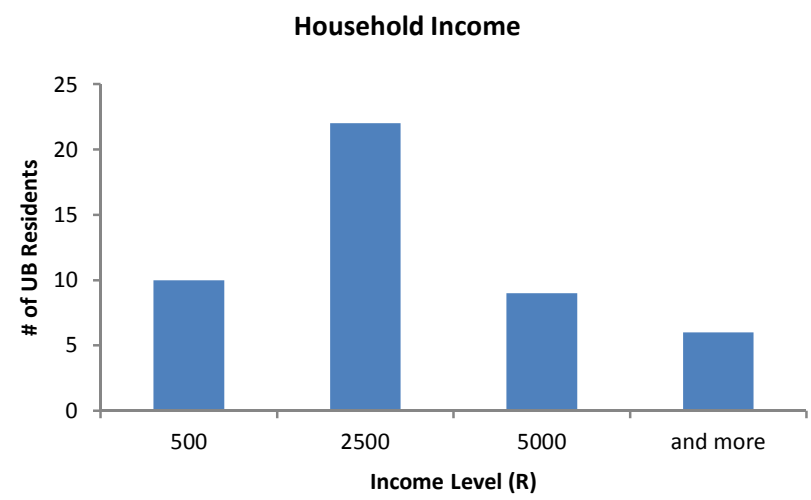

Fig. 19: Household income histogram

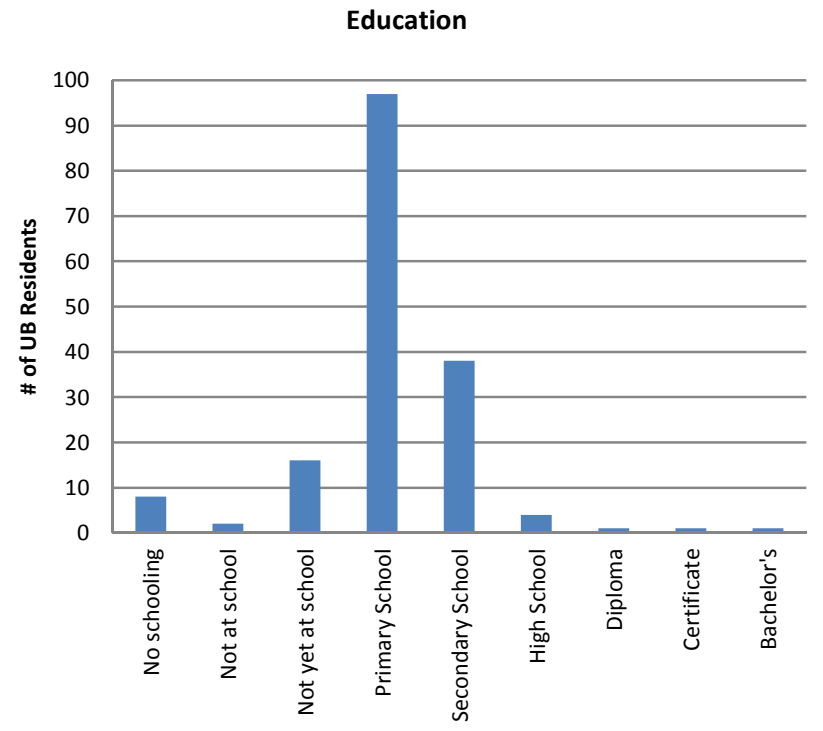

Fig. 20: Education histogram

\section{CONCLUSION}

Implementing a monitoring system for the mini-grid in UB provides practical insights into the technical requirements for a sustainable, decentralized energy supply and the necessary framework conditions for other regions. Indirectly, other rural areas in Eastern Cape, South Africa, should benefit from the monitoring results, as the mini-grid project should serve as a template for the development of further mini-grids.

The MEF provides the opportunity to streamline the flow of real-time energy data (generation, consumption, and storage) from the system to generate accurate and high-resolution data-driven load profiles for rural households or communities. These profiles are used for studying and analyzing the evolution of demand and making ongoing design optimization and will be useful as a reference for mini-grid researchers and developers active in Sub-Saharan Africa.

Joint monitoring of the institutional integration promotes the development of regulatory frameworks for so-called mini-grids and decentralized electricity supply scenarios.

Project stakeholders are located in Germany and South Africa, therefore, the coordination and communication is critical in the process.

The plan is to collect data from the system on a continuous basis for a sufficiently long period of time (i.e. 5-year period) to allow research university partners to conduct appropriate analysis and draw relevant results contributing to the common goal of the project. 
The community will be used as a "living lab" by South African universities and research facilities to study the development and evolution of energy demand and the desired feedback on local prosperity [11].

The future plan is to integrate machine learning methods to establish a correlation between renewable energy forecasting, household load profile generation and the social development progress to further improve the study.

\section{Acknowledgment}

As part of a joint project between South Africa's Eastern Cape province and Germany's state of Lower Saxony, with funding from BMZ (Federal Ministry for Economic Cooperation and Development) through GIZ (Deutsche Gesellschaft für Internationale Zusammenarbeit), a PV hybrid mini-grid was designed and developed in the municipality of UB in the Eastern Cape, South Africa.

South African Partners:

- Department of Economic Development, Environmental Affairs and Tourism (DEDEAT)

- Raymond Mhlaba Local Municipality

- University of Fort Hare

- Nelson Mandela University

- The Council for Scientific and Industrial Research (CSIR)

- South Africa Wind Energy Project (SAWEP)

- United Nations Development Programme (UNDP)

- Global Environment Facility (GEF)

- South African National Energy Development Institute (SANEDI)

- Department of Minerals Resources and Energy (DMRE)

\section{References}

[1] United Nations, "The Sustainable Development Goals Report 2019," UN, New York, 2019.

[2] World Bank, "Sustainable Energy for All ( SE4ALL ) database from the SE4ALL Global Tracking Framework led jointly by the World Bank, International Energy
Agency, and the Energy Sector Management Assistance Program," Access to electricity (\% of population), ID:

EG.ELC.ACCS.ZS, 2019. [Online]. Available: https://data.worldbank.org/indicator/EG.ELC.ACCS.ZS. [Accessed 1002 2020].

[3] IEA, ""SDG7: Data and Projections", IEA, https://www.iea.org/reports/sdg7-data-and-projections," Paris, 2019.

[4] G. Davies, "AFRICA IN FOCUS, Building the grid of the future, today," 2017. [Online]. Available: https://www.brookings.edu/blog/africa-infocus/2017/10/10/building-the-grid-of-the-future-today/. [Accessed 1010 2019].

[5] O. M. Longe, K. Ouahada, H. C. Ferreira and S. Chinnappen, Renewable Energy Sources microgrid design for rural area in South Africa, ISGT 2014, Washington, DC, 2014.

[6] IRENA, 'Off-grid renewable energy solutions: Global and regional status and trends', Abu Dhabi.: ISBN 97892-9260-076-1, 2018.

[7] S. C. Dubey and C. Morris, "World Bank Blogs," 2 October 2018. [Online]. Available: Sunita Chikkatur Dubey, Catherine Morris, A new chapter for SubSaharan Africa's mini grids industry, OCTOBER 02, 2018, retrieved

frohttp://blogs.worldbank.org/nasikiliza/a-new-chapterfor-sub-saharan-africas-mini-grids-industry. [Accessed 1510 2019].

[8] Departament of Energy, Republic of South Africa, Integrated Resource Plan (IRP 2019), South Africa, October, 2019.

[9] CSIR, Integrating off-grid solutions into South Africa's electrification programme,

http://www.cityenergy.org.za/uploads/resource_426.pdf, May 2017.

[10] Eskom, "GCCA 2022 Update Interactive Map," 2020. [Online]. Available: http://www.eskom.co.za/Whatweredoing/GCCAReport/ Pages/GCCA2022UpdateInteractiveMap-.aspx. [Accessed 02 2020].

[11] Kühnel, Hanke, Baranova, Weigel, Stuermer, McMaster, Maebe and v. Maydell, "Design of Hybrid-Minigrids in a South African Rural Areas under consideration of social and cultural Aspects," in EU PVSEC, 2018.

[12] "Global Solar Atlas 2.0, a free, web-based application is developed and operated by the company Solargis s.r.o. on behalf of the World Bank Group, utilizing Solargis data, with funding provided by the Energy Sector Management Assistance Program (ESMAP).," [Online]. Available: https:/globalsolaratlas.info/map?r=ZAF\&c=28.671449,24.67085,6.

[13] IRENA, "Off-grid renewable energy solutions to expand electricity access: An opportunity not to be missed, International Renewable Energy Agency," Abu Dhab, 2019. 
[14] D. S. Heunis and M. Dekenah, "load profile prediction model for residential consumers," in "Domestic use of energy 2010" conference Cape Town March 2010, reprinted in energize - May 2010 - Page 49, Cape Town, May 2010.

[15] The World Bank, UN, "Accelerating sdg 7 achievement, policy brief 15, Tracking SDG 7.1 with the multi-tier framework, measuring energy access," Published by the United Nations, 2019.

[16] M. BLUNK, Electricity and sustainable development: Impacts of solar home systems in rural bangladesh, Mainz, Germany: Department of Geography of the Johannes Gutenberg. University of Mainz., 2008.

[17] United Nations (2005B), The Social Summit Ten Years Later, New York: United Nations, 2005.

[18] Udjo, Orkin and Simelane, "Levels of social indicators in south africa in relation to international goals of development," in Economic Commission for Europe Seminar: Statistics for Social Development, Geneva 2000 and Beyond, Geneva 2000 Forum, Geneva, 2000.

[19] S. SZEWCZUK, "Hybrid mini-grid systems: Distributed generation systems for communities based on renewable energy resources," The Council for Scientific and Industrial Research (CSIR), Built Environment, Pretoria, South Africa., 2009.

[20] K. V. RAMANI and E. HEIJNDERMANS, Energy, Poverty And Gender: A Synthesis, The International Bank for Reconstruction and Development., 2003.

[21] United Nations, "Renewable energy technologies for rural development," in UNITED NATIONS CONFERENCE ON TRADE AND DEVELOPMENT UNCTAD, New York and Geneva, 2010.

[22] S. S. RATHI and C. VERMAAK, "Rural electrification, gender and the labor market: A cross-country study of india and south africa," 2018.

[23] M. MADZIGA and R. RAHIL, "Electrification using a hybrid microgrid system for mutate masisi community a demand side response," Journal of Environmental \& Analytical Toxicology., 2018.

[24] T. DINKELMAN, The effects of rural electrification on employment: New evidence from South Africa, University of Michigan., 2008.

[25] K. Kaygusuz, Energy Services And Energy Poverty For Sustainable Rural Development, Vol. 15 ed., 2011, pp. 936-947.

[26] A. C. L., P. Klintenberg, F. Wallin, B. Karlsson and C. Mbohwa, Electricity For Development: Mini-grid Solution For Rural Electrification In South Africa., Vol. 110 ed., 2016, pp. 268-277.

[27] S. S. Rathi and C. Vermaak, Rural Electrification, Gender And The Labor Market: A Cross-country Study Of India And South Africa, Vol. 109 ed., 2018, pp. 346359.
[28] P. O'Malley, The Reconstruction And Development Programme (RDP), The O'Malley Archives, 2017.

[29] B. Malmberg, Demography And Social Development, Vol 16. ed., 2007, pp. 21-34.

[30] M. Durieux, "The Role Of Social Grants In Supporting Local Economic Development (LED). Building Up

Knowledge To Break Down Poverty," Studies in poverty and inequality institute. Policy Brief, Johannesburg, South Africa, 2012.

[31] D. Mitra, "The Social and Economic Benefits of Public Education," Pennsylvania State University, Pennsylvania, USA, 2011.

[32] P. Boreham, J. Povey and W. Tomaszewski, \{Work and social well-being: the impact of employment conditions on quality of life, 27 ed., Routledge, 2015, pp. 593-611.

[33] Statistics South Africa,, "The state of basic service delivery in South Africa: In-depth analysis of the Community Survey 2016 data," 30 March 2017.

[34] World Bank, Rural Energy and Developmentfor Two Billion People, Washington DC, USA: World Bank, The World BankVice Presidency for Finance andPrivate Sector DevelopmentIndustry \& Energy Department, 2003.

[35] M. Juliá and M. E. Kondrat, Health care in the social development context: Indigenous, participatory and empowering approaches., vol. 48(5), 2005, p. 537-552.

[36] M. I. Aceleanu, Links Between Education, Employment And Quality Of Life. The Case Of Romania, Vol. 7, No. 4 ed., Academy of Economic Studies, Bucharest, 2012, pp. 717-730.

[37] H. Jeong, Demographic changein the Republic of Korea:Policy lessons for other Asia-Pacific countries, 2019.

[38] ECSECC, Eastern Cape Socio Economic Consultative Council, "RAYMOND MHLABA LOCAL

MUNICIPALITY SOCIO ECONOMIC REVIEW AND OUTLOOK," April 2017. [Online]. Available:

https://www.ecsecc.org/documentrepository/information centre/raymond-local-municipality_12336.pdf.

[39] World Data, "Energy consumption in South Africa," 2019. [Online]. Available:

https://www.worlddata.info/africa/south-africa/energyconsumption.php. [Accessed 1001 2020].

[40] Stats SA, 2017. [Online]. Available: http://rodra.co.za/images/countries/south_africa/research /P03182017\%20household\%20survey\%20stats\%20sa.pd f. 